\title{
Assessment of variceal pressure by continuous non-invasive endoscopic registration: a placebo controlled evaluation of the effect of terlipressin and octreotide
}

\author{
F Nevens, W Van Steenbergen, S H Yap, J Fevery
}

\begin{abstract}
Octreotide has been proposed for the treatment of variceal bleeding. The effects on portal pressure, however, have been variable in published studies. As bleeding is more directly related to pressure in the varices, this study investigated the effect on variceal pressure of octreotide and terlipressin, a vasoactive drug with a well established effect. Variceal pressure was measured during four to eight minutes by a continuous non-invasive endoscopic registration method. Thirty patients in whom a stable variceal pressure recording had been obtained during at least one minute, were randomised to receive either $2 \mathrm{mg}$ terlipressin, $50 \mu \mathrm{g}$ octreotide or an identical volume of saline, as a single intravenous injection given over 60 seconds. For the final analysis three patients had to be excluded because of lack of a satisfactory recording. There were no significant clinical differences between the three groups of patients. Placebo administration did not induce significant changes, but a mean decrease in variceal pressure of $-27 \%$ was noted with terlipressin, starting from two minutes onwards. Variceal pressure changes after injection of octreotide were variable and the mean change in pressure did not reach statistical significance. Seven of 10 patients showed a temporary increase in variceal pressure. In conclusion, terlipressin induces a significant and progressive decrease in variceal pressure but inconsistent variations of variceal pressure changes were seen after octreotide administration. This is probably related to its effect on central venous pressure. This study also shows that continuous variceal pressure recording with the non-invasive endoscopic registration technique detects in an accurate way the
\end{abstract}

method most commonly used, is the measurement of the hepatic venous pressure gradient (HVPG). A HVPG above $12 \mathrm{~mm} \mathrm{Hg}$ is required to develop a variceal haemorrhage but a direct relation between HVPG and the risk of variceal bleeding is lacking. ${ }^{1}$ Recent investigations confirm that variceal pressure (VP) bears a much closer relation with the risk of bleeding than the $\mathrm{HVPG}^{2}$ and that the risk of early rebleeding after variceal haemorrhage is significantly higher in patients who did not experience a significant reduction in VP. ${ }^{3}$ Furthermore, the reduction in HVPG can underestimate the effect of the drug on the VP. ${ }^{4}$ As a consequence, direct measurement of the effect of pharmacological agents on VP is receiving more attention.

VP can be measured by the fine needle puncture technique, but as this invasive method is usually restricted to patients receiving sclerotherapy, it has a limited application. Measurement of VP with a hemispheric, pneumatic pressure gauge, has been claimed to be highly accurate in acute conditions. ${ }^{5}$ As the technique is not invasive, it can be performed in any patient. The effect of a drug on VP has usually been assessed by repeated measurements in acute conditions. Such registration of VP can be hindered, however, by spontaneous or swelling induced oesophageal contractions. Furthermore, intermittent measurements, even in acute conditions may overlook rapid changes in VP. ${ }^{6}$

The efficacy of terlipressin (Glypressin), a slow release form of vasopressin, in the treatment of acute variceal bleeding was shown in several placebo controlled studies. ${ }^{7-9}$ In agreement with this clinical finding, a reduction in VP, as measured by the fine needle puncture method, has been reported. ${ }^{10}$ Octreotide, a synthetic long acting analogue of somatostatin has recently been propagated for the treatment of variceal haemorrhage. The effects of octreotide on portal pressure in cirrhotic patients, however, differed greatly in various studies. ${ }^{1-14}$ Furthermore, increases of intravariceal pressure after octreotide administration have been reported. ${ }^{15}$ It was therefore the aim of this investigation to reconsider in a placebo controlled way the effect of octreotide and terlipressin on VP over a prolonged period of time. For this purpose we recorded the VP continuously with a non-invasive variceal pressure gauge.

Methods

Thirty patients in whom a stable VP recording \footnotetext{
effect of vasoactive drugs on variceal pressure, because placebo injection did not produce significant changes.

(Gut 1996; 38: 129-134)

Keywords: portal hypertension, variceal bleeding, variceal pressure, terlipressin, octreotide.

A variety of clinical investigations are currently available to evaluate the degree of portal hypertension and to assess the effect of pharmacological agents on portal pressure. Until now the

Correspondence to:

Dr J Fevery, Department of University Hospital Gasthuisberg, Herestraat 49 Accepted for publication

12 July 1995

and Pancreas

Hospital Gasthuisberg, Leuven,

W Van Steenbergen

S H Yap
} 
was obtained during at least one minute, were randomised blindly to receive either $2 \mathrm{mg}$ terlipressin (Glypressin), $50 \mu \mathrm{g}$ octreotide (Sandostatin), a dose currently proposed by the company for the arrest of a variceal

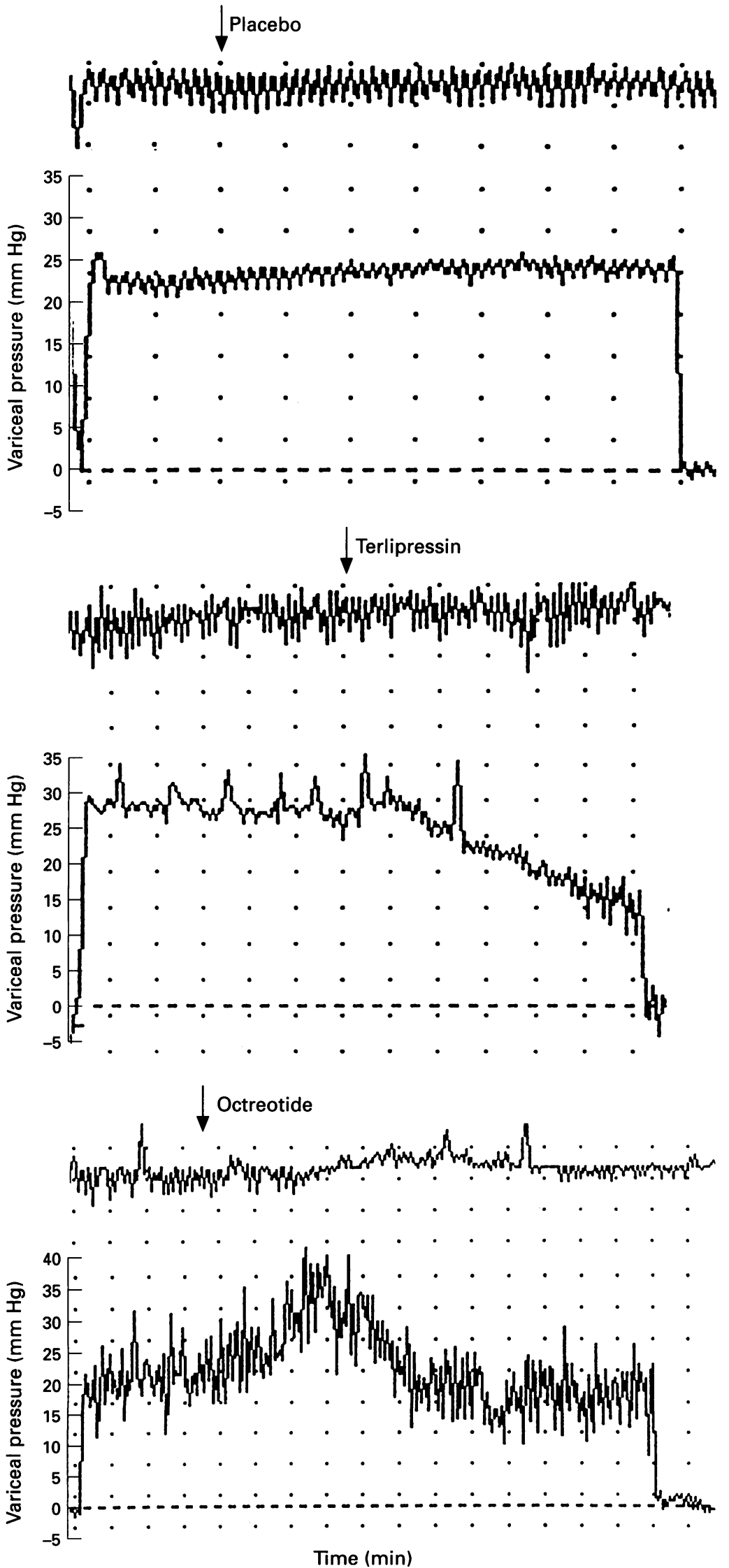

Figure 1: Continuous VP recording with the pneumatic gauge after an intravenous bolus injection of saline (upper part), terlipressin $2 \mathrm{mg}$ (middle part), and octreotide $50 \mu \mathrm{g}$ (lower part). haemorrhage or an identical volume of saline, as a single intravenous injection given over 60 seconds. The identity of the injection remained unknown to the medical investigators. Randomisation was performed using the system of sealed envelopes. For the final analysis, three patients had to be excluded before the code was broken because pressure recordings were unsatisfactory over a sufficient length of time. Of the final study group, 17 patients were men and 10 were women; the ages ranged from 25 to 72 years with a mean age of 59 . All patients had cirrhosis; 11 belonged to ChildPugh class A, seven to class $B$, and nine to class C. None of the patients had received endoscopic sclerotherapy before.

Measurements of VP were carried out at endoscopy by using a previously described non-invasive technique (Varipress, Labotron, Barcelona, Spain). ${ }^{16}$ In this study we used an adapted small hemispheric pressure gauge, with an external diameter of $6 \mathrm{~mm}(7.5 \mathrm{~mm}$ with rubber ring) and a measuring surface of $4.5 \mathrm{~mm}$, attached to the distal end of an endoscope. The gauge has a small chamber, covered by a latex membrane that is perfused by a constant flow of nitrogen. When applied over a varix, the pressure needed to perfuse the gauge equals the pressure inside the varix. The Varipress system was connected to a pressure transducer (Novotrans, Medex) and pressure values were recorded continuously by a PC polygraf (Synetics Medical, Stockholm, Sweden). The system was calibrated before each measurement by using an artificial varix; this consists of a column of water with a $U$ shaped lower end of a diameter of $15 \mathrm{~mm}$ and covered by a latex membrane of $75 \mu \mathrm{m}$ thickness. The pressure on this latex membrane can be altered by changing the height of the water column in the other arm. The gauge has a fast upstroke velocity and can reach $30 \mathrm{~mm} \mathrm{Hg}$ in less than 0.5 seconds. Oesophageal luminal pressure was recorded simultaneously by a continuous water perfusion system by a catheter attached to the outer surface of the endoscope. This system was calibrated by raising the tube to varying heights.

After intravenous scopolamine administration and at the moment capsule pressure in the free position reached its basal and stable level, the gauge was gently applied on the varix. Air insufflation in the oesophagus before and after each application was avoided. The force of application was increased and the recording of VP was considered satisfactory when stable and fine venous fluctuations superimposed on the respiratory cycle were recognised in the absence of pronounced luminal contractions (Fig 1).

Capsule pressure was calculated as the mean of the upper and lower fluctuations recorded. VP was expressed as the difference between the intravariceal (capsule pressure) and the intraluminal pressure of the oesophagus (IP), which represents the transmural pressure gradient of the varices. This provides a better estimate of the risk of bleeding than the absolute intravascular pressure. ${ }^{17}$ The pressure needed to perfuse the gauge while it is not in contact with 
any structure, registers the oesophageal luminal pressure and the mean of the upper and lower fluctuations was used as the zero reference. The mean oesophageal luminal pressure compared with atmospheric pressure, was $2.9 \mathrm{~mm} \mathrm{Hg}$ (range $0 \cdot 0-6 \cdot 3$ ) in 50 consecutive VP measurements previously performed in our laboratory.

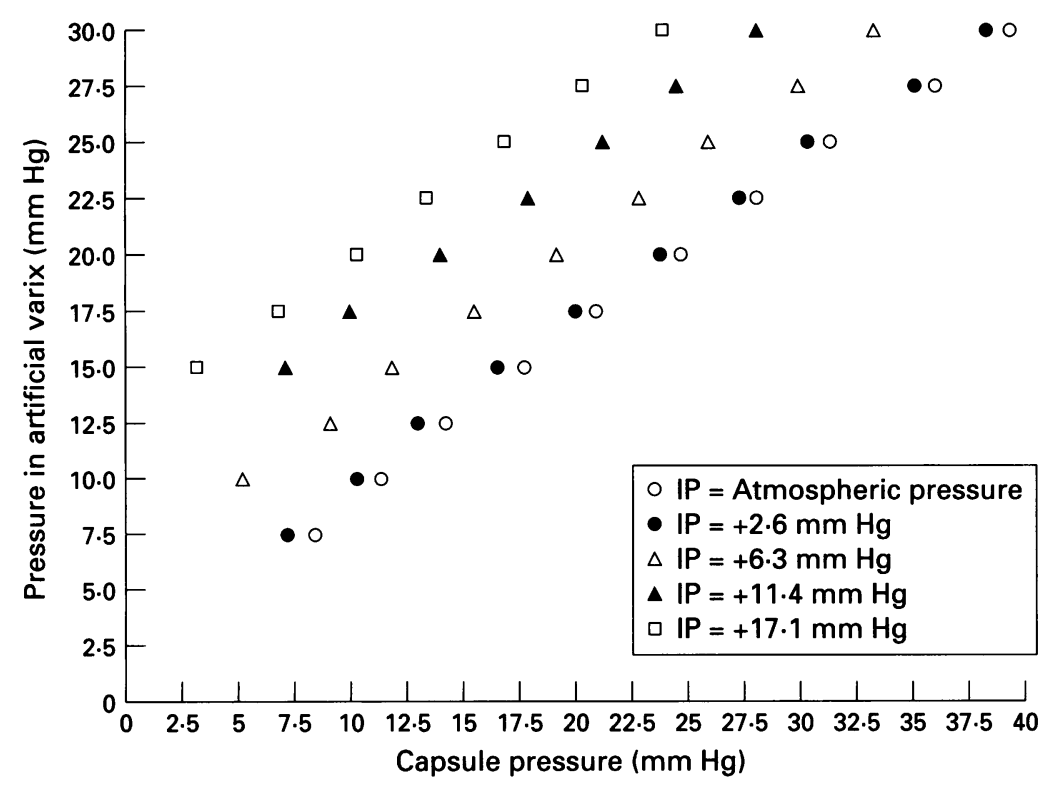

Figure 2: Effect of changes of the IP of the oesophagus on the recordings. Changes of the IP are mimicked in this in vitro experiment by immersion of the artificial varix system in a water bath at variable depth (from 2.6 to $17.1 \mathrm{~mm} \mathrm{Hg}$ ). Pressure in the artificial varix was changed by increasing the water column in the feeding tube (from 7.5 to $30 \mathrm{~mm} \mathrm{Hg}$ ). Capsule pressures were obtained by applying the gauge under water on the artificial varix. When the pressure in the artificial varix system was kept constant, the gauge (capsule pressure) registered progressively lower values when the mimicked intraluminal pressure was increased. At oesophageal luminal pressures of 2-4 $\mathrm{mm} \mathrm{Hg}$ capsule pressure was a valuable estimate of the intravariceal pressure. Note that at intravariceal pressures above $20 \mathrm{~mm}$ $\mathrm{Hg}$, capsule pressure tend to overestimate intravariceal pressure.
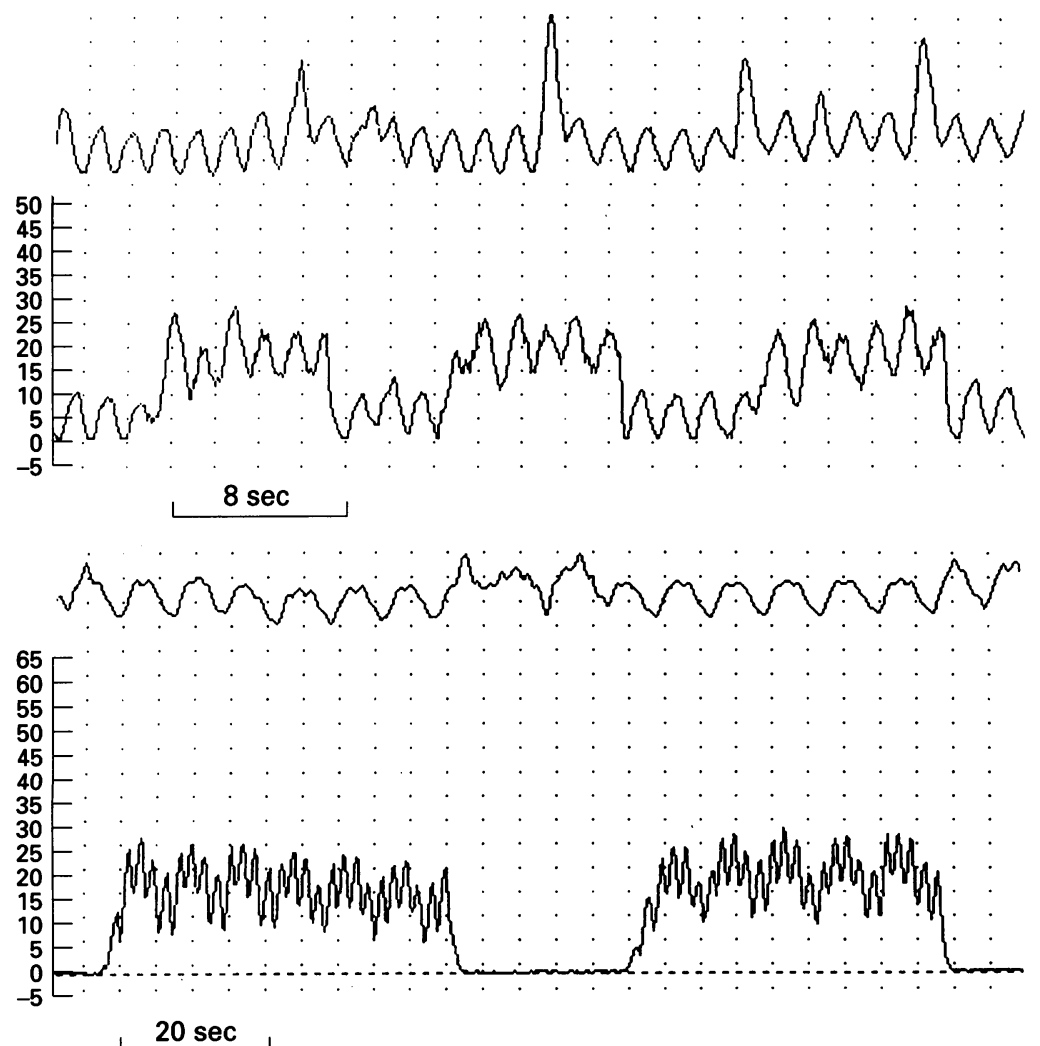

Figure 3: Pattern of VP tracing close to the cardia (top) and close to the aortic arch (bottom). The IP in the oesophagus is recorded simultaneously (upper tracing).
Changes in oesophageal luminal pressure might influence VP registration. The influence of changes in luminal pressure was therefore studied previously to this study in vitro by immersion of the artificial varix system as described previously at different heights in a water bath. The capsule was applied under water on the artificial varix system. Figure 2 gives the results. A high oesophageal luminal pressure, created in this in vitro study by the water in the bath will lead to a capsule pressure that underestimates intravariceal pressure but at oesophageal luminal pressures of $2-4 \mathrm{~mm} \mathrm{Hg}$ capsule pressure is a valuable estimate of intravariceal pressure. In contrast, luminal contractions transmitted to the capsule can artificially overestimate VP. For this second reason, oesophageal luminal registration has been recorded simultaneously by another tube and registration of VP was performed for long enough until a stable recording was obtained.

Application of the capsule slightly on the lateral side of the varix is preferential, as it avoids the capsule slipping off during respiration movements. Optimal tracings are obtained when the veins can cover the whole capsule. Varices with a diameter below $5 \mathrm{~mm}$ may not give such a good contact between the capsule and the varix, thus enabling the noncompressible surrounding tissue to interfere with the capsule pressure measurement. The pattern of the tracings depends on the location of the gauge in the oesophagus. Variceal pressure measurements carried out close to the cardia are characterised by pronounced and slow fluctuations similar to those registered by the oesophageal channel (Fig 3). Pressures recorded close to the aortic arch are characterised by heavy and sharp fluctuations not recorded by the oesophageal catheter; these are induced by pulsations transmitted by the large arterial vessels (Fig 3 ). Because of these environmental artefacts, these positions should be avoided. A sudden and forceful application provokes a sharp increase of pressure above $50 \mathrm{~mm} \mathrm{Hg}$ and will usually induce an oesophageal contraction. Pressure recordings performed during routine endoscopy may, however, have many artefacts even after scopolamine administration, these must be eliminated by repeated measurements on the same varix. At least four to five satisfactory recordings should be obtained. Therefore this

Clinical and endoscopic characteristics

\begin{tabular}{lcll}
\hline & $\begin{array}{l}\text { Saline } \\
(n=9)\end{array}$ & $\begin{array}{l}\text { Glypressin } \\
(n=8)\end{array}$ & $\begin{array}{l}\text { Octreotide } \\
(n=10)\end{array}$ \\
\hline Mean age (y) & $61(14)$ & $59(8)$ & $58(17)$ \\
Male/female & $6 / 3$ & $6 / 2$ & $5 / 5$ \\
$\begin{array}{l}\text { Aetiology of portal hypertension (n) } \\
\quad \text { Posthepatitis B, C }\end{array}$ & 2 & 2 & 1 \\
$\quad$ Cryptogenic & 5 & 1 & 1 \\
$\quad$ Alcoholic & 1 & 3 & 3 \\
$\quad$ Miscellaneous & 1 & 1 & 2 \\
$\quad \begin{array}{l}\text { PBC } \\
\text { Child-Pugh score }\end{array}$ & 0 & 1 & 3 \\
$\begin{array}{l}\text { Size of the varices (mm) } \\
\text { Presence of red colour } \\
\text { signs (n) }\end{array}$ & $7(3)$ & $9(3)$ & $7(2)$ \\
$\begin{array}{c}\text { Baseline variceal pressure } \\
\text { (mm Hg) }\end{array}$ & 5 & $7(2)$ & $8(1)$ \\
\hline
\end{tabular}

Data are expressed as numbers or mean (SD). 
way of recording is less suitable for investigating the rapid effects of drugs on VP. To overcome this problem, the capsule was held in this study in the same position on the varix for at least four minutes after bolus administration of the drug under investigation.

\section{Statistical analysis}

One way analysis of variance with repeated measurements was performed to evaluate pressure changes in function of time. Analysis of covariance was performed at each time point taking the baseline pressure into account.

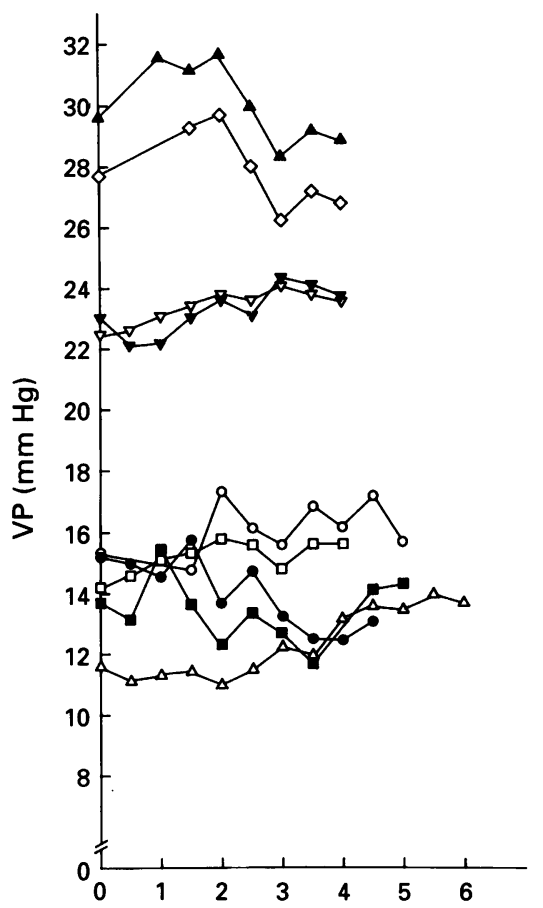

Placebo

\section{Results}

Three patients (one in the placebo group and two in the terlipressin group) had to be excluded because of exaggerated oesophageal contractions $(n=1)$ or because of the loss of contact of the capsule with the varix before the end of the minimum of four minutes registration time $(n=2)$. The Table gives the clinical and endoscopic characteristics of the final nine patients receiving placebo, the eight receiving terlipressin, and the 10 patients receiving octreotide. There was no significant difference between the three groups with regard to age, sex, aetiology of the liver disease, liver function, the size and the aspect of the varices, and the baseline variceal pressure.
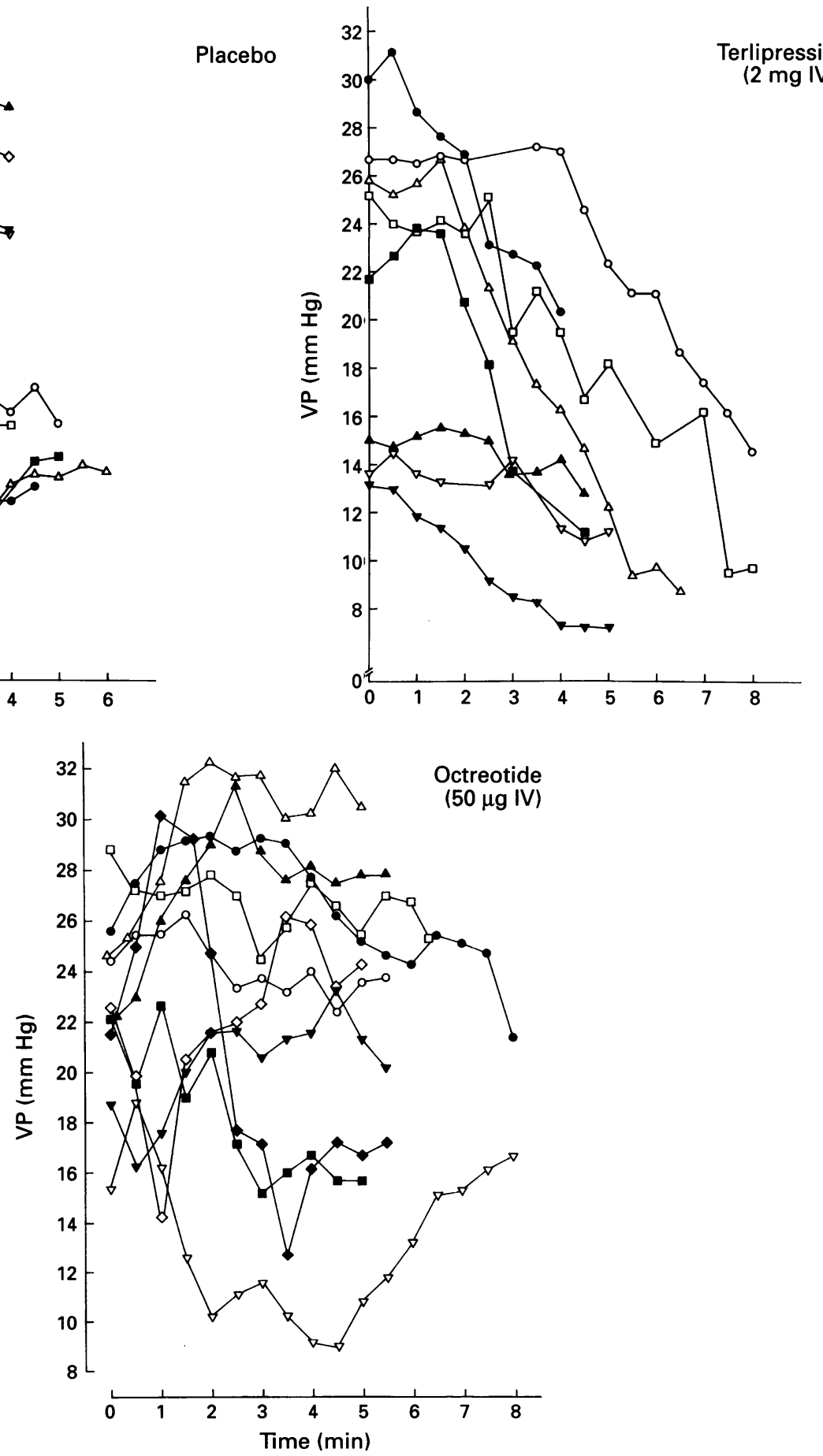

Figure 4: VP values measured in individual patients after intravenous (IV) administration of placebo, terlipressin, or octreotide. 

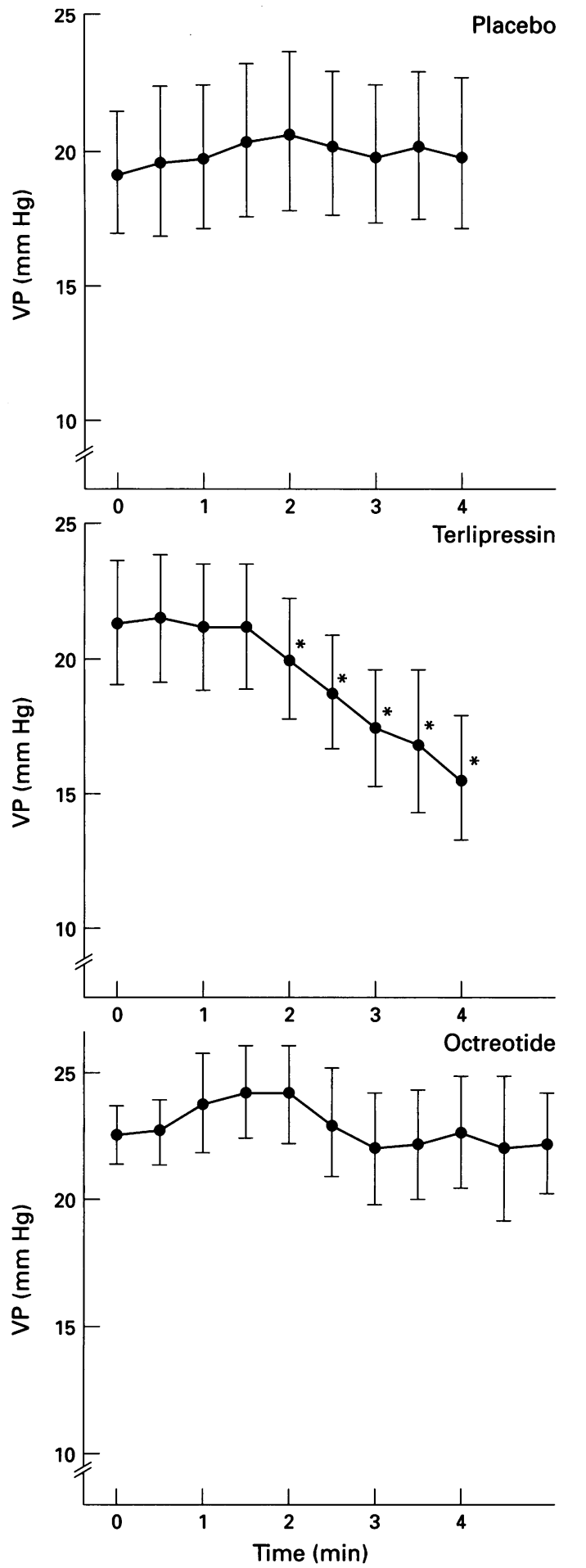

Figure 5: Mean (SEM) values of the measurements of VP after intravenous administration of placebo, terlipressin, or octreotide. Only the pressure changes after terlipressin were statistically significant $\left({ }^{\star} p<0 \cdot 001\right)$.

Figure 1 represents the recordings of variceal pressure and oesophageal luminal pressure during the different drug administrations. The upper part of the figure shows the effect of placebo, the middle part the influence of a bolus injection of $2 \mathrm{mg}$ of terlipressin, and the lower part one of the different recording patterns after a bolus injection of $50 \mu \mathrm{g}$ of octreotide.

Figure 4 shows the VP for each patient at onset until eight minutes after placebo, terlipressin or octreotide administration. In contrast with the placebo administration, a general decrease in VP caused by terlipressin was noted but it was less obvious in two patients with rather lower baseline VP. VP changes after octreotide administration were variable. In four patients a drop in pressure was noted and in two patients this occurred after an initial slight increase in pressure; in five patients, however, an increase in pressure was seen and this occurred after an initial drop in pressure in two patients; and in one patient no significant changes were seen. In fact seven of 10 patients had a temporary increase in VP during the registration period after octreotide administration.

In the patients treated with terlipressin a significant drop in VP was recognised after two minutes and this decrease continued further on. No significant changes in pressure were seen in the placebo group and octreotide group. The changes in pressure (mean (SEM)) after terlipressin, octreotide, and placebo at four minutes were $-27 \%(7),-1 \%(7)$, and $-2 \%$ (4), respectively (Fig 5). The pressure changes did not correlate with the height of the basal pressure in either group. The bolus drug administrations were tolerated without any problem. One patient, however, presented a period of clinical bradycardia and hypotension three hours after administration of terlipressin.

\section{Discussion}

There is increasing interest in the determination of VP since it was shown that VP shows a closer relation with the risk of variceal bleeding than the hepatic venous pressure gradient. ${ }^{2} \mathrm{VP}$ measurements can be obtained either by direct puncture of a varix ${ }^{18}$ or with a pressure sensitive capsule. ${ }^{19}$ Because the second technique is non-invasive, it deserves a wider use. One of the potential uses of such a device is the direct assessment of the response to pharmacological treatment on VP. However, this requires a high degree of precision. The potential risk that changes in capsule position, changes in oesophageal luminal pressure, or changes in oesophageal motility would interfere with VP determination should therefore be eliminated. Intermittent measurements even in acute conditions may overlook rapid changes in VP as we have recently shown by the invasive intravariceal puncture technique when using somatostatin. ${ }^{6}$

When the Varipress capsule is continuously kept in the same position on the varix, changes in oesophageal luminal pressure and induction of oesophageal contraction can be reduced to a minimum, as was shown in this study by analysing the placebo group. This technique allowed us to show that the administration of $2 \mathrm{mg}$ of terlipressin induced a significant decrease in VP, from two minutes after injection onwards. A broad range of changes in VP was seen after octreotide administration with even a temporary increase in VP being seen in $70 \%$ of the patients.

The observed effects of terlipressin on VP are completely in accordance with those published by Cestari et al ${ }^{10}$ who used the fine needle puncture technique. The late onset of 
the effect of the drug is in agreement with the slow release structure of the molecule. As noted in other studies, two of our patients with comparatively low baseline VP values (13.1 and $13.6 \mathrm{~mm} \mathrm{Hg}$, respectively), failed to show a significant decrease in VP. Cestari et al ${ }^{10}$ suggested that their method of recording VP was probably too insensitive to detect small reductions in pressure in cases of low VP values, but with our technique VP values of only $8 \mathrm{~mm} \mathrm{Hg}$ can be detected in an appropriate way. We therefore suggest that these patients represent true non-responders. The percentage of non-responders in pharmacological studies with terlipressin agrees with the percentages $( \pm 20 \%)$ of haemorrhages not controlled by the drug in clinical trials. ${ }^{7-9}$

A significant drop in azygos blood flow ${ }^{13}$ and in portal venous flow velocity ${ }^{20}$ after octreotide administration is a general finding. However, the effect of the drug both on portal pressure and systemic haemodynamics is still controversial ${ }^{12-14}$; and even an increase of VP has been reported. ${ }^{15}$ In this study a temporary increase in VP was noted in most of our patients. Some studies showed, however, that octreotide is as effective for the control of variceal bleeding as balloon tamponade, ${ }^{12}$ vasopressin, ${ }^{21}$ terlipressin, ${ }^{22}$ or sclerotherapy. ${ }^{23}$ Kleber et al ${ }^{24}$ reported a similar increase in VP with somatostatin 14 and suggested that this increase in VP could be explained by a raised cardiopulmonary pressure. The variable effect on VP found in our patients after a bolus administration of octreotide can result indeed from a great individual variability of the effect of the drug on central venous tonus, which can explain at the same time both the decrease in azygos flow and the lack of effect on portal pressure found in previous studies. Concomitant registration of changes in central venous pressure and VP should elucidate this hypothesis further.

In conclusion, we confirmed that terlipressin, a slow release form of vasopressin, induces a significant and progressive decrease in VP, which starts from two minutes onwards and reaches a $27 \%$ decrease in VP at four minutes. A wide variety of VP changes were seen after octreotide administration. This is probably related to a concomitant effect on central venous pressure but needs further research.

Finally, we showed that continuous VP recording with the pneumatic gauge Varipress detects in an accurate way the effect of terlipressin and octreotide on VP as placebo injection did not produce significant changes. This device might thus be used to explore the acute effects of drugs for the treatment of portal hypertension.

The help of the endoscopy nurses Mr T De Greef and Miss M Francen is greatly appreciated. We thank Miss A Goethuys for typing the manuscript.
1 Garcia Tsao G, Groszmann RJ, Fisher RL, Conn HO, Attenburg CE, Glickman M. Portal pressure, presence of gastroesophageal varices and variceal bleeding. Hepatology 1985; 5: 419-24.

2 Rigau J, Bosch J, Bordas JM, Navasa M, Mastai R, Kravetz $\mathrm{D}$, et al. Endoscopic measurement of variceal pressure in cirrhosis: correlation with portal pressure and variceal hemorrhage. Gastroenterology 1989; 96: 873-80.

3 Ruiz del Arhol L, Arocena C, Vazquez M, Defarges V, Maroño E, Garcia Plaza A, et al. Endoscopic measurement of variceal pressure (VP) during haemorrhage from esophageal varices (HVE). F Hepatol 1992; 16: S36.

4 Feu F, Bordas JM, Luca A, García-Pagán JC, Escorsell A, Bosch J, et al. Reduction of variceal pressure by propranolol: comparison of the effects on portal pressure and azygos blood glow in patients with cirrhosis. Hepatology 1993; 18: 1082-9.

5 Feu F, Bordas JM, García-Pagán JC, Bosch J, Rodés J. Double-blind investigation of the effects of propranolol and placebo on the pressure of esophageal varices in patients with portal hypertension. Hepatology 1991; 13: 917-22.

6 Nevens F, Sprengers D, Fevery J. The effect of different doses of a bolus injection of somatostatin combined with a slow infusion on transmural oesophageal variceal pressure in patients with cirrhosis. $\mathcal{F}$ Hepatol 1994; 20: 27-31.

7 Walker S, Stiehl A, Raedsch R, Kommerell B. Terlipressin in bleeding eosphageal varices. A placebo controlled double-blind study. Hepatology 1986; 6: 112-5.

8 Freeman JG, Cobden MD, Record CO. Placebo-controlled trial of terlipressin (Glypressin) in the management of acute variceal bleeding. F Clin Gastroenterol 1989; 11 $58-60$.

9 Soderlund C, Magnusson I, Torngren S, Lundell L. Terlipressin (triglycyl-lysine vasopressin) controls acute bleeding oesophageal varices. A double-blind, randomized, placebo-controlled trial. Scand $\mathcal{F}$ Gastroenterol 1990; 25: $622-30$.

10 Cestari R, Braga M, Missale G, Ravelli P, Burroughs AK. Haemodynamic effect of triglycyl-lysine-vasopressin (glypressin) on intravascular oesophageal variceal pressure in patients with cirrhosis. A randomized placebo controlled trial. $₹$ Hepatol 1990; 10: $205-10$.

11 Eriksson LS, Brundin T, Söderlund C, Wahren J. Hemodynamic effects of a long-acting somatostatin analogue in patients with liver cirrhosis. Scand $f$ Gastroenterol 1987; 22: 919-25.

12 McKee R. A study of octreotide in oesophageal varices. Digestion 1990; 45: 60-5.

13 MacCormick PA, Dick R, Siringo S, Wagstaff D, Chesta J, McIntyre N, et al. Octreotide reduces azygos blood flow in cirrhotic patients with portal hypertension. Eur $\mathfrak{f}$ Gastroenterol Hepatol 1990; 2: 489-92.

14 Lin HC, Tsai YT, Lee FY, Lee SD, Hsia HC, Lin WJ, et al. Hemodynamic evaluation of octreotide in patients with hepatitis B-related cirrhosis. Gastroenterology 1992; 103: 229-34.

15 Primignani M, Vazzoler MC, Carpinelli L, Nolte A, Hall de Lima MC, Arcidiacono PG, et al. The effect of octreotide in intraesophageal variceal pressure in liver cirrhosis is unpredictable. Hepatology 1990; 12: 989.

16 Bosch J, Bordas JM, Rigau J, Viola C, Mastai R, Kravetz D, et al. Noninvasive measurement of the pressure of esophageal varices using an endoscopic gauge: comparison with measurements by variceal puncture in patients undergoing endoscopic sclerotherapy. Hepatology 1986; 6: 667-72.

17 Hosking SW, Robinson P, Johnson AG. Effect of Valsalva's manoeuvre and hyoscinbutylbromide on the pressure gradient across the wall of oesophageal varices. Gut 1987; 28: $1151-6$.

18 Staritz M, Poralla T, Meyer zum Büschenfelde $\mathrm{KH}$. Intravascular oesophageal variceal pressure (IOVP) assessed by endocopic fine needle puncture under basal conditions, Valsalva's manoeuvre and after glyceryltrinitrate application. Gut 1985; 26: 525-30.

19 Mosimann R. Nonaggressive assessment of portal hypertension using endoscopic measurement of variceal pressure. Am f Surg 1982; 143: 212-4.

20 Kapicioglu S, Ovali E, Yesildag O, Baki AH. Effects of somatostatin on portal venous velocity in cirrhotic patients: a placebo-controlled trial. Gastroenterology 1992; 3: 22-6.

21 Hwang SJ, Lin HC, Chang CF, Lee FY, Lu CW, Hsia HC, et al. A randomized controlled trial comparing octreotide and vasopressin in the control of acute esophageal variceal and vasopressin in the control of acut
bleeding. F Hepatol 1992; 16: 320-5.

22 Silvain C, Carpentier S, Sautereau D, Czernichow B, Métreau JM, Fort E, et al. Terlipressin plus transdermal nitroglycerin vs octreotide in the control of acute bleeding from esophageal varices: a multicenter randomized trial. Hepatology 1993; 18: 61-5.

23 Sung J, Chung SCS, Lai CW, Chan FKL, Leung JWC, Yung MY. Octreotide infusion or emergency sclerother24 Kleber G, Sauerbruch T, Fisher G, Paumgartner G. Somatostatin does not reduce oesophageal variceal pressure in liver cirrhotics. Gut 1988; 29: 153-6. 